\title{
Under the Background of the New Era, the Research of Improvement Path on Young Teachers' Class Teaching Level of Colleges
}

\author{
WANG Junhu \\ College of marxism, shaanxi international business university, Xi'an, 712046, China \\ Corresponding author. Email:270562144@qq.com
}

\begin{abstract}
Young people have become the main force of teachers in colleges. In order to help them pass the barrier in teaching, the paper indicates the advantages, disadvantages and common problems of young teachers in classroom teaching, based on the practice of teaching supervision and management. Some suggestions are put forward to improving classroom quality from the school leadership and management aspect, and also the young teachers themselves. The systematic long-term mechanism of young teachers training system, tutorial system, policy guidance of performance distribution, scientific appraisal and incentive mechanism is the objective guarantee conditions. Meanwhile, young teachers' understanding of teaching status and inputs is the subjective decision factors. Both of them are indispensable.
\end{abstract}

Keywords: young teachers, classroom teaching, colleges

\section{新时代背景下民办本科高校青年教师课堂教学水平 的制约因素及其提升路径研究}

\author{
王军虎
}

(陕西国际商贸学院马克思主义学院, 陕西 西安 712000)

通讯作者: 270562144@@qq.com

摘要:

青年教师已经成为民办本科高校教师队伍的生力军，为了帮助他们过好教学关，基于教学工作的实践 与思考，指出民办本科高校青年教师从事课堂教学的优势、不足和存在的共性问题，并从学校领导与 管理部门、青年教师自身成长两个路径提出青年教师不断提升课堂教学质量的思路和建议。其中学校 建立系统的青年教师培训体系、青年教师导师制、绩效分配的政策导向、科学的考评和激励等长效机 制是提高教学质量的客观保障条件，青年教师自身对教学地位的认识和投入力度是主观决定因素，二 者缺一不可。

关键词：青年教师；课堂教学；民办本科高校 
存在重科研轻教学的现象, 认为 “科研是硬杜子,

\section{1. 引言}

随着我国高等教育的快速发展, 越来越多的青年人加入 高校教师队伍, 在民办本科高校中, 年龄在 35 岁以下的青 年教师一般占到专任教师总数的 $40 \%-50 \%$, 个别院校还要高 一些, 他们已经成为或者将要成为高校教学和科研的生力 军。高校的首要职能和根本任务是通过教育教学培养人才 ${ }^{[1]}$, 课堂教学是实施人才培养的主要途径之一, 青年教师的课堂 教学水平对高校人才培养质量有着举足轻重的影响。本文基 于教学管理工作的观察和思考, 从民办高校青年教师队伍现 状出发, 指出青年教师课堂教学过程中常见的几个问题, 并 分别从学校管理部门建立教师教学考评和奖惩长效机制、老 教师的传帮带和青年教师个人努力等方面提出建议，旨在帮 助青年教师掌握基本教学技能, 全面提升课堂教学质量, 迅 速成为地方高校教学的骨干力量。

\section{2. 民办本科高校青年教师课堂教学的优劣势分 析}

学历高、知识新、有活力, 是民办高校青年教师的优势。 民办本科高校 35 岁以下青年教师中均具有硕士研究生或以 上学历。他们对学科新动向和前沿了解较多, 容易学习和掌 握新的教学理念和教学手段, 再者他们精力充沛, 学习和工 作效率高; 相对于 985、211 等重点大学而言, 民办高校本 科教学任务重, 青年教师一旦走上工作岗位, 就要独当一面 承担一定的课堂教学任务, 在比较短的时间内实现学生到教 师的角色转变, 使他们承受的心理和精神压力比较大 ${ }^{[2-4]}$; 缺 乏经验是青年教师的劣势, 他们从教时间短, 相对来讲没有 练就扎实的教学基本功, 教学模式单一, 缺乏教学经验和驾 驭课堂的能力。再加上相当一部分青年教师毕业于非师范专 业, 没有受过系统的教师教育的培训, 缺乏教育理论的指导 和教育实践的经历。

\section{3. 民办本科高校青年教师课堂教学存在的主要 问题}

大多数青年教师经过三到五年的锻炼, 能够掌握基本的 课堂教学技能, 成长为合格的甚至是优秀的高校教师。但也 有少数青年教师由于各种原因导致课堂教学水平提升较慢, 甚至入职几年以来进步不大, 存在的共性问题主要有以下几 个方面。

\section{1 教学投入不足}

青年教师如果不能正确的处理生活、教学、科研、管理 等诸多方面的问题, 不能科学合理地分配时间和精力, 势必 影响对教学工作的投入力度, 从而影响课堂教学的质量。如 在面对教学和科研双重工作压力时, 有相当一部分青年教师
教学是软尺子”，他们觉得只要把科研搞上去就会 名利双收, 课堂教学只要完成规定的工作量就可以 了, 至于课堂教学的质量马马虎虎过得去就行。由 于认识上的偏差, 使得部分青年教师急功近利, 对 教学工作不认真，投入的精力严重不足。

\section{2 备课不充分}

教师对课程的准备是否充分直接影响到课堂 教学的质量。有些青年教师对教学内容不熟悉, 讲 课条例不清楚, 重点不突出, 难点讲不透, 离不开 教材或课件等现象，均说明教师没有下功夫备课。 另外, 现阶段高校采用的绝大部分教材都附有多媒 体课件和电子教案, 网络媒体上也有许多可以共享 的课程资源, 这些均为高校教师备课提供了方便。 但有一部分教师对这些素材没有经过自己的理解 和加工, 一味的 “拿来” 和 “照搬” , 甚至连一本 属于自己的完整教案都没有, 这又是备课不充分的 另一种表现。

\section{3 过分依赖多媒体等现代教学手段}

冊需置疑, 如果能科学合理地运用多媒体等现 代教学方法, 不仅可以为课堂教学带来无限活力与 生机, 而且能明显提升教学效果, 但如果盲目和过 度使用, 往往会事与愿违。因为多媒体技术只是一 种辅助教学的工具, 它不可能取代教师在教学中的 主导地位和引导作用, 而有些青年教师对多媒体课 件过度依赖, 把整个教学过程演变成单调的人与计 算机的交互, 根本没有进行师生间的有效交流与互 动。甚至有少数青年教师形成了典型的 “多媒体满 堂灌” 和填鸭式教学, 从头至尾忙碌于课件放映, 完全不考虑作为学习主体的学生以及学生的感受, 没有给学生留出足够的时间让他们进行必要的思 考和讨论, 此乃课堂教学的 “硬伤” 和大忌 ${ }^{[5]}$ 。

\section{4 缺乏与学生的有效互动和交流}

无论采用什么媒体进行教学, 课堂教学都是一 个以学生为主体和以教师为主导进行双向交流的 过程, 教师正确的引导和高效的组织管理, 是决定 课堂教学成功的首要因素。高校教师应通过形象生 动的语言表达、启发诱导、设置问题等方式, 加强 与大学生的交流和互动, 从而营造生动活泼的课堂 气氛, 这样才能取得良好的教学效果。而我们经常 会看到一些青年教师在课堂上滔滔不绝地讲授, 恨 不得把自己知道的所有知识都讲给学生听, 学生无 法参与教学活动之中, 只能被动的听讲; 或者走 向另一个极端, 只是呆板地播放课件, 平淡无奇地 


\section{1.4 完善考评机制, 加大教学奖惩的力 度}

建立科学合理的教师评价和考核体系, 引导青 年教师以 “教学为本”, 不断提高专业素养和教 育教学水平。目前在地方高校不同程度的存在着重 科研轻教学的倾向。建议对青年教师考核的权重适 度向教学倾斜, 一方面对教学效果优秀的青年教师 加大宣传和奖励的力度, 另一方面对学生评价差、 教学考核不合格的青年教师在晋升职称和考核中 实行 “教学一票否决制”。

\section{2 民办本科青年教师的个人成长}

\subsection{1 爱岗敬业, 为人师表}

教学是教师的立足之本, 青年时期正是一位教 师教学规范养成和技能奠基的关键阶段, 可能会对 今后十几年乃至几十年的教学水平都会产生影响。 因此, 青年教师要着眼长远和未来, 对工作高度负 责, 苦练教学本领, 提倡 “教无止境” , 不断提高 并创新教学。

\section{2.2 认真备课, 因才施教}

青年教师要投入充足的时间和精力认真备课, 加强对课程的理解 ${ }^{[8]}$, 并且做到 “备教材、备课件、 备学生”。大学教育与中小学基础教育不同的是, 每门课程没有指定的统编教材, 而同一门课程有多 种教材和课件并存。教师在备课的过程中应该以教 学大纲为依据, 以选用教材为参考, 汲取其他教材 的精华, 结合学生的知识背景和个性特点, 形成知 识结构合理、内容丰富的教案和课件, 为实施高效 的课堂教学奠定良好的基础。

\section{2. 3详略得当, 引导自学}

教师要精心设计教学内容, 掌握好课堂教学节 奏, 条理清楚, 主次有别, 为学生提供适量的教学 信息, 不断提高掌控和驾驭课堂的能力, 从而提升 个人鬼力。经常会遇到一些青年教师上课节奏很 快, 忙着赶进度, 抱怨 “课时少、内容多”。其实 只要在教学内容处理上, 做到 “突出重点、抓住难 点、引导自学”, 这个问题就会迎刃而解。在有限 的课堂教学时间内, 必须把教学内容有效的区分为 “详讲”、“略讲” 和 “自学” 等知识层次, 课堂 讲述内容上应多增加一些和课程主题有关, 细节无 关的有深度和趣味的内容, 以扩展学生的知识面 ${ }^{[9]}$, 这样不仅可以保证较高的课堂教学质量和效率, 而 
且能够引导学生自学并考察学生分析问题和解决问题的能 力, 同时也可以促使教师了解和反思教学效果 ${ }^{[10]}$ 。

\subsection{4 现代多媒体与传统媒体有机整合}

与传统媒体相比, 现代多媒体有其明显的优势和先进 性，但它不能完全替代其他媒体的作用，更不能为了使用多 媒体而抛弃传统媒体 ${ }^{[13]}$ 。任何一种教学媒体都有其自身的特 点和优势, 在教学过程中, 青年教师应根据课程和讲授内容 的特点, 选择合适的媒体组织教学, 并注重与其他媒体的有 机结合, 形成不同的组合教学。无论采用什么组合教学方式, 黑板和板书是必不可少的, 因为在课堂教学的过程中, 教师 与知识点同步的讲解与板书往往对学生理解和巩固所学知 识有着不可替代的作用。

\section{5. 结语}

提高民办本科高校青年教师课堂教学质量是一个复杂 的系统工程。不仅需要学校构建系统的培训体系、科学合理 的考评和激励机制、政策和分配的正确导向、严格的教学奖 惩制度和青年教师导师制, 而且要求青年教师树立教学为本 的理念, 爱岗敬业, 教书育人。虚心向优秀教师学习, 兢兢 业业完成备课、上课、辅导答疑、批改作业等教学环节, 认 真总结和反思教学效果, 充分发挥学历高、知识新、有活力 的优势, 尽快掌握课堂教学技能, 提高教育教学质量, 使自 己成长为优秀的高校教师。

\section{REFERENCES}

[1]Zhou yuanqing. Improving quality is the key to education reform and development $[\mathrm{J}]$. China higher education research, 2011 (11) : 4-7.

[2] Li xiaojie, cycad bear. Investigation and analysis of the current situation of young teachers in colleges and universities [J]. Journal of north China university (social science edition), 2007,23 (S1) : 109-112.

[3]Yang Xiaozhi. Sources and countermeasures of pressure on young teachers in colleges and universities -- a research based on the investigation of colleges and universities in Beijing [J]. Heilongjiang higher education research, 2013,31 (10) : 95-97.

[4]Wang yuqing, gan fengchun, duan wenjie. The source of new teachers' pressure and its relationship with their mental health [J]. Contemporary teacher education, 2016,9 (1) : 28-34.

[5] Ma lu, yu shujie, yuan long, long xuan, he yi. Common mistakes in multimedia teaching and their countermeasures [J]. Health vocational education. 2006,24 (3) : 75-76.

[6]Zhou yuanqing. My teaching reform [J]. China higher education research, 2015 (9) : 1-3.

[7]Liu zhengyi. Teaching in universities is still in a state of "partiality" $[\mathrm{J}]$. China higher education research, 2015 (11) : 3-4.

[8]Li lihua. Analysis on the deviation of teachers' curriculum value orientation in curriculum implementation -- a case study of Chinese teachers [J]. Journal of hebei normal university (education science edition), 2014,16 (1) : 119-123.

[9]Li xiying. Flipped classroom and teaching innovation of ideological and political courses in universities -- an attempt to take "basic courses" as an example [J]. Journal of hebei normal university (education science edition), 2016,18 (2) : 99-104.

[10]Wang shu-li, sha desheng. Application of multimedia technology in classroom teaching [J]. Adult education. 2003,23 (Z2) : 71. 